\title{
Salmonella Enteritidis Effector AvrA suppresses autophagy by reducing Beclin-1 protein
}

Yang Jiao ${ }^{\mathrm{a}}$, Yong-guo Zhang ${ }^{\mathrm{a}}$, Zhijie Lin ${ }^{\mathrm{a}}$, Rong Lu ${ }^{\mathrm{a}}$, Yinglin Xia ${ }^{\mathrm{a}}$, Chuang Meng ${ }^{\mathrm{a}}$, Zhimin $\mathrm{Pan}^{\mathrm{b}}$, Xiulong $\mathrm{Xu^{c }}$, Xinan Jiao ${ }^{\mathrm{b}}$, Jun Sun ${ }^{\mathrm{a}}$

${ }^{a}$ Division of Gastroenterology and Hepatology, College of Medicine, University of Illinois at Chicago, Chicago, IL, 60612, USA

${ }^{b}$ Jiangsu Key Laboratory of Zoonosis, Jiangsu Co-innovation Center for Prevention and Control of Important Animal Infectious Diseases and Zoonosis, Yangzhou University, Yangzhou, 225009, Jiangsu Province, China

${ }^{\mathrm{c}}$ Rush University, Chicago, IL, 60612, USA

\section{Running title}

Salmonella Enteritidis AvrA suppresses autophagy

\section{Corresponding author}

Jun Sun, PhD, AGAF, FAPS

Professor

Division of Gastroenterology and Hepatology, Department of Medicine

Department of Microbiology/lmmunology

UIC Cancer Center

University of Illinois at Chicago

840 S Wood Street, Room 704 Clinical Science Building, MC716

Chicago, IL, 60612

Tel: 312-996-5020 E-mail: junsun7@uic.edu 


\section{Abstract:}

Autophagy is a cellular process to clear pathogens. Salmonella enterica serovar Enteritidis (S.E) has emerged as one of the most important food-borne pathogens. However, major studies still focus on Salmonella enterica serovar Typhimurium. Here, we reported that AvrA, a $S$. Enteritidis effector, inhibited autophagy to promote bacterial survival in the host. We found that AvrA regulates the conversion of LC3 I into LC3 II and the enrichment of lysosomes. Beclin-1, a key molecular regulator of autophagy, was decreased after AvrA expressed strain colonization. In S.E-AvrA--infected cells, we found the increases of protein levels of $\mathrm{p}-\mathrm{JNK}$ and $\mathrm{p}$-c-Jun and the transcription level of AP-1. AvrA-reduction of Beclin-1 protein expression is through the JNK pathway. The JNK inhibitor abolished the AvrA-reduced Beclin-1 protein expression. Moreover, we identified that the AvrA mutation C186A abolished its regulation of Beclin-1 expression. In addition, AvrA protein interacted with Beclin-1. In organoids and infected mice, we explored the physiologically related effects and mechanism of AvrA in reducing Beclin-1 through the JNK pathway, thus attenuating autophagic responses.

\section{Importance:}

Salmonella Enteritidis is an important pathogen with a public health concern and farm production risk, yet the host-pathogen interactions that govern the survival of $S$. Enteritidis infections are incompletely understood. Anti-bacterial autophagy provides potent cell-autonomous immunity against bacterial colonization. Here, we report that a new role for effector AvrA of $S$. Enteritidis in the reduction of Beclin-1 protein expression through the JNK pathway and the attenuation of the autophagic response in intestinal epithelial cells. This finding not only indicates an important role of $S$. Enteritidis effector in reducing host protein as a strategy to suppress autophagy, but also suggests manipulating autophagy as a new strategy to treat infectious diseases. 
bioRxiv preprint doi: https://doi.org/10.1101/2020.01.13.905596; this version posted January 14, 2020. The copyright holder for this preprint (which was not certified by peer review) is the author/funder. All rights reserved. No reuse allowed without permission.

Key words: Autophagy, effector; infection; organoids; Paneth cells 


\section{Introduction}

Salmonella is a Gram-negative, facultative anaerobe and an intracellular pathogen to both humans and animals. Salmonella enterica serovar Enteritidis has emerged as one of the most important food-borne pathogens for humans, and it is mainly associated with the consumption of contaminated poultry meat and egg $(1,2)$. Infection caused by Salmonella Enteritidis is the second most common cause of bacterial gastroenteritis in the developed world, and results in significant economic loss to the poultry industry and places a substantial burden on the healthcare system (2-4). Salmonella Enteritidis is an important pathogen with a public health concern, thus demanding further studying. However, the majority of basic researches in Salmonella field still focus on Salmonella enterica serovar Typhimurium (Salmonella Typhimurium) to study host-microbial interactions.

Autophagy pathway and proteins balance the beneficial and detrimental effects of immunity and inflammation, and thereby may protect against infectious (5). To survive in host cells, Salmonella use mechanisms to prevent clearance from host cells, such as escaping from the phagosome, inhibiting phagosome-lysosome fusion, and inhibiting apoptosis and autophagy in host cells (6-12). Among the numerous host defense systems against pathogens, anti-bacterial autophagy provides potent cell-autonomous immunity against bacterial attempts to colonize the cytosol of host cells $(5,13-15)$. During this process, the phagophore expands and engulfs pathogens, and closes to originate the autophagosome that fuses with the lysosome, at which the degradation of the pathogens takes place (16). There are more than 20 ATG proteins (many of which are evolutionarily conserved) that are essential for the execution of autophagy (17). Notably, the mammalian autophagy protein Beclin-1, an ortholog of the Atg6 in yeast, is a key molecule regulator of autophagy. Beclin-1 interacts with several cofactors (e.g. 
Atg14L, HMGB1, IP3R, PINK, and survivin) to regulate the lipid kinase Vps-34 protein and promote the formation of Beclin-1-Vps34-Vps15 core complexes, thereby inducing autophagy $(18,19)$.

Salmonella possesses a range of effector proteins that are translocated into the host cells via a type III secretion system (T3SS). These effector proteins are generally assumed to influence the host's cellular functions to facilitate Salmonella invasion and intracellular carriage (20-23). AvrA is one of the Salmonella effectors secreted by the Salmonella pathogenicity island 1 (SPI-1) T3SS. The AvrA protein in Salmonella Typhimurium is an anti-inflammatory effector that possesses acetyltransferase activity and inhibits the host c-Jun N-terminal kinase (JNK)/AP-1 and NF-KB signaling pathways. Through these methods, AvrA inhibits the host inflammatory response and stabilizes the intestinal tight junctions to the benefit of bacterial survival $(9,24-28)$. However, the role of AvrA in Salmonella infection and host autophagic response is unexplored.

Here, we hypothesize that Salmonella Enteritidis effector AvrA inhibits the autophagic response by decreasing Beclin-1 expression. We used wild-type, Salmonella Enteritidis C50336 and established a deletion Salmonella Enteritidis mutant S.E-AvrA and a plasmid-mediated complementary strain S.E-AvrA $/$ pAvrA $^{+}\left(\right.$S.E-AvrA $\left.{ }^{+}\right)(28)$. In cell cultures, organoids and infected mice, we explored the physiologically related effects and molecular mechanism of AvrA regulation of autophagy in intestinal epithelial cells, whereas most studies on bacterial effectors and autophagy only use cell cultures. Our study provides new insights into the mechanisms of the bacterial effects in regulating host-microbial interactions. 


\section{Results}

\section{Salmonella Enteritidis AvrA decreases autophagy markers and enhanced bacterial}

invasion in vitro. Autophagy is an important cell-autonomous defense mechanism required for pathogen clearance $(13,14)$. LC3 and p62 are well-recognized markers for autophagic activity (29). In this study, we found that in human intestinal epithelial HCT116 cells, the conversion of LC3 I into LC3 II was increased after S.E-AvrA- infection compared to that after wild-type S.E or S.E-AvrA infection. Notably, p62, which is a bona fide target of autophagosomal degradation, was decreased in the cells infected with the S.E-AvrA mutant strain compared with the expression in cells infected with the S.E-WT or S.E-AvrA ${ }^{+}$strains (Fig. 1A). A densitometry analysis showed a significant difference between the cells infected with the different S.E strains (Fig. 1B, C). Meanwhile, HCT116 cells pre-treated with LysoTracker showed more lysosomes in the cells infected with the S.E-AvrA mutant strain than in the cells infected with the AvrA expressed strains (Fig. 1D, E). The role of AvrA in Salmonella Enteritidis invasion is unknown. We further compared the invasion ability of Salmonella Enteritidis strains with or without AvrA expression. We found that S.E-AvrA- colonized human epithelial cells showed a decreased intracellular bacterial load compared to those colonized with wild type S.E or S.E-AvrA+ (Fig. 1F). We observed similar trends in autophagic activity following S.E-AvrA', S.E-AvrA ${ }^{+}$and S.E-WT infection in human Caco-2 BBE and SKCO15 cells (data not shown). Taken together, these data suggest that the Salmonella Enteritidis effector AvrA inhibits autophagy in vitro.

\section{AvrA reduces Beclin-1 at the protein levels and interacts with Beclin-1. Beclin-1, a} key molecular regulator of autophagy, interacts with several cofactors to regulate the lipid kinase Vps-34 protein and promote the formation of Beclin-1-Vps34-Vps15 core 
complexes, thereby inducing autophagy $(18,19)$. Thus, we determined whether the protein level of Beclin-1 was changed by the infection with the different S.E strains. As shown in Fig. 2A and 2B, Beclin-1 protein expression was significantly decreased after colonization of the AvrA present strains for 1 hour. In contrast, the cells colonized with the S.E-AvrA bacteria maintained Beclin-1 protein expression. To verify that AvrA affects the protein expression of Beclin-1, we transfected an AvrA WT plasmid or an AvrA C186A mutant [mutated at the key cysteine required for AvrA activity (24)] plasmid into HCT116 cells. As expected, the AvrA WT plasmid decreased endogenous Beclin-1 protein expression. However, the AvrA C186A mutant plasmid maintained the endogenous Beclin-1 protein expression (Fig. 2C, D,). We further determined the interaction of AvrA/Beclin-1 in the HCT116 cells by immunoprecipitation. Vps34 was used as a positive control. We found that exogenous AvrA (c-myc tag) coimmunoprecipitated with exogenous Beclin-1 (HA- tag), suggesting that AvrA interacted with Beclin-1 (Fig. 2E). Therefore, the data suggest that the S.E effector AvrA interacts with Beclin-1 and changes the Beclin-1 protein level to inhibit autophagy.

AvrA inhibits the JNK signaling pathway to decrease Beclin-1. Beclin-1 is regulated by the JNK signaling pathway (30). Previous studies have shown that Salmonella AvrA inhibits the activation of the JNK signaling pathways $(9,28)$. Using Western blotting, we found that the protein levels of $p$-JNK and $p$-c-Jun were higher in the S.E-AvrA-infected cells than in the cells infected by the S.E-WT or S.E-AvrA ${ }^{+}$strains (Fig. 3A). Meanwhile, a luciferase reporter assay showed that AP-1 transcription was increased, as a consequence of the activation of JNK/C-JUN (Fig. 3B). These data suggest that the $\mathrm{JNK} / \mathrm{C}$-jun pathway and AP-1 transcription are more highly activated in the S.E-AvrAinfected cells than in the cells infected with the AvrA present strains. Interestingly, after treatment with the JNK inhibitor SP600125, the level of Beclin-1 and P62 protein 
expression was not different between the cells infected with AvrA or without AvrA (Fig. $3 \mathrm{~A}, \mathrm{~B})$, indicating that the AvrA-related responses were abolished by the JNK inhibitor. Thus, our data indicate that the S.E effector AvrA inhibits the autophagic response by decreasing Beclin-1 at the protein level, and it occurs by inhibiting the JNK/C-Jun/AP-1 signaling pathways.

\section{The AvrA mutant C186A plasmid expression abolishes the regulation of} exogenous Beclin-1 expression. To further study the function of the AvrA protein, we cotransfected an AvrA WT plasmid or an AvrA C186A mutant plasmid with a Beclin-1 WT plasmid. The AvrA C186A mutation is known to abolish the enzyme activity of AvrA (24). Our data showed that the AvrA WT plasmid decreased not only the endogenous Beclin-1 protein but also the exogenous Beclin-1 protein. In contrast, the AvrA C186A mutant plasmid abolished its regulation on Beclin-1 expression (Fig. 4A, B). Moreover, we found that the protein levels of p-JNK, p-c-Jun and Beclin-1 were decreased in the AvrA WT plasmid transfected cells compared with the cells transfected with the AvrA C186A mutant plasmid. These data verified that AvrA decreased Beclin-1 by inhibiting the JNK signaling pathways, whereas the AvrA C186A mutation abolished its regulation (Fig. 4C). We did not observe the change of the Beclin-1 at the mRNA level (data not shown).

\section{AvrA expressing bacteria reduce the level of Beclin-1 protein in mouse organoids.}

Intestinal organoid culture is a newly developed 3D system to determine the bacterialepithelial interactions post Salmonella infection (31). We found that the Beclin-1 protein expression was significantly decreased after the infection of the S.E-WT expressing AvrA. In contrast, the organoids colonized with the S.E-AvrA mutant strain increased Beclin-1 protein expression, whereas S.E-AvrA ${ }^{+}$could reduce the Beclin-1 expression 
(Fig. 5A, B). Moreover, we found AvrA-associated changes of P62, LC3 II / LC3 I, and p-JNK in the Salmonella-infected organoids (Fig. 5A, C, D). Decreased autophagy marker P62 was further confirmed in organoids colonized with the S.E-AvrA- strain in comparison with organoids infected by the S.E-WT and S.E-AvrA ${ }^{+}$strains by Immunostaining (Fig. 5E). These changes in the 3D organoids were consistent with AvrA-suppressed autophagy observed in the 2D cultured cell lines.

\section{AvrA changes the levels of Beclin-1 and affects the function of Paneth cell granules of the ileal tissues in a mouse model.}

To study the role of the S.E effector AvrA in an in vivo model of natural intestinal infection, we used the streptomycin pretreatment mouse model of enteric salmonellosis $(32,33)$. C57BL/6 mice (female, 6-8 weeks) were pretreated with streptomycin for 24 hours before infection with the S.E-WT, S.E-AvrA or S.E-AvrA ${ }^{+}$strains by oral gavage. In the lleum samples from the S.E-WT-infected mice, Beclin-1 protein expression was significantly decreased compared to the expression in the samples from the S.E-AvrAinfected mice (Fig. 6A, B). As expected, decreased P62, increased conversion of LC3 I into LC3 II and activation of the JNK pathway were also found in mice infected with the S.E-AvrA strain compared with those in the mice infected by the S.E-WT strain (Fig. 6A, C, D). These data suggest that AvrA inhibits the JNK signaling pathway to decrease Beclin-1 expression and impair the autophagic response in vivo.

Deficits in the autophagy pathway impair Paneth cell function in intestine $(34,35)$. Thus, we counted the number of Paneth cells using a previously reported method to stain lysozymes $(35,36)$. The abnormal Paneth cells were grouped as D1 (disordered), D2 (depleted), or D3 (diffuse) (Fig. 6E). We found fewer normal Paneth cells (D0) in the mice infected with the S.E-WT strain than in the mice infected with the S.E-AvrA- strain 
(Fig. 6E, F). Consequently, the number of abnormal Paneth cells (D1-D3) increased in the mice infected with the wild-type S.E strain (Fig. 6F).

\section{Discussion}

In the current study, we report that the $S$. Enteritidis effector protein AvrA decreased Beclin-1 protein expression, thus impairing the autophagic response, for the benefit of Salmonella survival. AvrA-mediated regulation of host autophagy involves blocking the JNK signaling pathway, which was demonstrated in vitro and in vivo (Fig. 7E). The $S$. Enteritidis effector protein AvrA inhibited the JNK signaling pathways in epithelial cells, impaired autophagy by decreasing Beclin-1 expression at the protein level in vitro and in vivo, and affected the function of Paneth cell granules in a mouse model. Moreover, the JNK inhibitor SP600125 abolished the AvrA-reduced Beclin-1 protein expression. Together, these data suggest that the S.E effector AvrA inhibits the JNK/C-Jun/AP-1 signaling pathway to decrease Beclin-1 expression. In this way, Salmonella Enteritidis impairs the autophagic response to the benefit of the pathogen's survival. Moreover, AvrA affected the function of Paneth cell granules, potentially by inhibiting autophagy (Fig. 7E).

The AvrA from $S$. Typhimurium is known as an anti-inflammatory effector that possesses acetyltransferase activity toward specific host MAPKKs and inhibits the host JNK/C-Jun/AP-1 and NF-KB pathways, but the role of AvrA from $S$. Enteritidis is less explored $(9,24-28)$. Here, we demonstrated that $S$. Enteritidis AvrA inhibited the autophagic response. Beclin-1 protein levels were reduced with AvrA present strain infection. In contrast, S.E-AvrA mutant strain infection maintained Beclin-1 protein expression. Earlier studies on the mechanism underlying the regulation of autophagy in cancer cells showed that the activation of the JNK pathway may be involved in the regulation of Beclin-1 expression, and the latter event could be responsible for the 
induction of the autophagic response (30). Blocking the JNK pathway might be the reason that AvrA decreases Beclin-1 expression. To verify our results, we used a specific JNK inhibitor SP600125 to block the JNK signaling pathway. After treatment with the JNK inhibitor SP600125, Beclin-1 protein expression did not differ between infection with and without AvrA. The results demonstrated that the $S$. Enteritidis effector AvrA inhibits the JNK/C-Jun/AP-1 signaling pathway to decrease Beclin-1 expression. Our data indicated that cysteine 186 is the key amino acid required for the AvrA regulation of Beclin-1 expression. We further demonstrated that the single mutation of Cys ${ }^{186}$ blocked JNK activity and abolished the AvrA-induced downregulation of Beclin-1. Thus, we have demonstrated a strategy that Salmonella Enteritidis used to impair the autophagic response to the benefit of the pathogen's survival.

In the current study, we observed that the S.E WT strain with AvrA expression and complementary strain induced weak autophagic activity, compared to the autophagic activity following S.E AvrA muant strain infection. Numerous lines of evidence indicate that Salmonella infection can activate robust host cell autophagy (37-39). This difference maybe due to the serotype difference. The existing research tends to use Salmonella Typhimurium to study the interaction between host autophagic activity and bacterial invasion. However, Salmonella Enteritidis, which belongs to another Salmonella serotype, could be much difference from Salmonella Typhimurium in host-adaptability, virulence, intracellular survival and so on (40-42).

Interestingly, our data showed that AvrA interacted with Beclin-1 and decreased the ubiquitination of Beclin-1 (Fig. S1). However, the detailed mechanism is unclear. Previous studies have shown that the ubiquitination of Beclin-1 enhances its association with Vps34 to promote Vps34 activity (43). Thus, AvrA may suppress Beclin-1 
ubiquitination to inactivate Vps34 activity, leading to the suppression of autophagy. Certainly, this hypothesis requires further study.

Here, we highlighted the organoid system for investigating the host-bacterial interactions. Our previous studies have demonstrated that the intestinal organoid culture is a newly developed $3 D$ system to study Salmonella infection $(31,44)$. Our data in the organoid system have shown that AvrA expressing bacteria reduce the levels of Beclin-1, thus suppressing autophagy in the host. In the future, human organoids could be used to further understand how bacterial effectors manipulate the host responses.

Paneth cells are specialized epithelial cells that are primarily located in the small intestine. The granules of Paneth cells contain AMPs- $\alpha-$ defensins, lysozyme, and secretory phospholipase A2 (45-47). Among these, lysozyme is a useful marker of the Paneth cell secretory granule (48). Our data showed that the normal expression pattern of the Paneth cells decreased in the mice infected with the AvrA present strain compared with that in the mice infected with the S.E-AvrA mutant strain. The ileum, after infection with the AvrA present strain, contained an increased proportion of Paneth cells with disorganized or diminished granules or exhibited diffuse cytoplasmic lysozyme staining. These findings suggest that AvrA impairs the autophagic response, and then, the autophagy affects the biosynthesis or quality control of the lysosomal pathway in the Paneth cell granules. Thus, there were fewer normal Paneth cells in the mice infected with the S.E-WT strain. Recently, a study showed that $S$. Typhimurium invaded Paneth cells, and the invasion was associated with an elevated number of $\mathrm{LC}^{+}$puncta in the Paneth cells (49). It is not clear whether $S$. Enteritidis interact with Paneth cells and affect autophagy through the AvrA effector. Alternatively, the Paneth cells with fewer granules might be a result of Paneth cell exhaustion (34), compensating for the changes 
elsewhere in the epithelium, due to the survival benefit of Salmonella caused by AvrA suppressing autophagy.

Taken together, our data reveal a new role for AvrA in S. Enteritidis in the reduction of Beclin-1 protein expression through the JNK pathway and the attenuation of the autophagic response in intestinal epithelial cells. Bacterial effector proteins paralyze or reprogram host cells to the benefit of the pathogens. Our findings indicate an important role of $S$. Enteritidis effector in reducing host protein as a strategy to suppress autophagy. Manipulating autophagic activity through the JNK pathway may be a novel therapeutic approach to treat infectious diseases. 


\section{Materials and Methods}

Animals and Ethics Statement. C57BL/6 mice (female, 6-8 weeks) were obtained from the Jackson Laboratory (Jackson Laboratory, Bar Harbor, ME, USA). All the animal work was approved by the University of Illinois at Chicago Committee on Animal Resources. Euthanasia was accomplished via sodium pentobarbital administration (100 mg per $\mathrm{kg}$ body weight, i.p.) followed by cervical dislocation. All procedures were conducted in accordance with the approved guidelines of the Committees on Animal Resources.

Bacterial strains and growth conditions. The wild-type Salmonella Enteritidis strain C50336 (S.E WT) was obtained from the National Institute for the Control of Pharmaceutical and Biological Products (NICPBP), China. The Salmonella Enteritidis AvrA mutant strain S.E-AvrA- was derived from C50336, and the AvrA complemented strain S.E-AvrA ${ }^{+}$was constructed as in previous studies by our laboratory (28). The bacteria and plasmids used in this study are listed in Table I. The bacterial growth conditions were as follows: the non-agitated microaerophilic bacterial cultures were prepared by inoculating $10 \mathrm{ml}$ of Luria-Bertani (LB) broth with $0.01 \mathrm{ml}$ of a stationary phase culture followed by an overnight incubation ( $>18$ hours) at $37^{\circ} \mathrm{C}(50)$.

Cell culture. Human epithelial HCT116, Caco-2 BBE, and SKCO-15 cells were maintained in Dulbecco's modified Eagle's medium (DMEM) supplemented with 10\% fetal bovine serum (FBS), streptomycin-penicillin and L-glutamine. Bacterial colony forming units (CFU) were determined by plating diluted cell lysates onto LB agar culture plates and incubating the cultures at $37^{\circ} \mathrm{C}$ overnight (28).

\section{Mouse intestinal organoid isolation, culture and passage. The mouse small} intestines were removed immediately after cervical dislocation. The stool was then 
flushed out with ice-cold PBS (penicillin, 100 I.U./mL/streptomycin, $100 \mu \mathrm{g} / \mathrm{mL}$ ), and the small intestines were dissected and opened longitudinally and cut into small $(\sim 1 \mathrm{~cm})$ pieces. The tissues were rocked in PBS with $2 \mathrm{mmol} / \mathrm{L}$ ethylenediamine tetraacetic acid (EDTA) for 30 minutes at $4^{\circ} \mathrm{C}$ and were then switched to PBS with $54.9 \mathrm{mmol} / \mathrm{L}$ Dsorbitol and $43.4 \mathrm{mmol} / \mathrm{L}$ sucrose. The tissues were then vortexed for 1-2 minutes and were filtered through a $70 \mu \mathrm{m}$ sterile cell strainer. The crypts were collected by centrifugation at $150 \mathrm{~g}$ for 10 minutes at $4^{\circ} \mathrm{C}$. Approximately 500 crypts were suspended in $50 \mu \mathrm{L}$ of growth factor-reduced phenol-free Matrigel (BD Biosciences, San Jose, CA). Next, a $50 \mu \mathrm{L}$ droplet of the Matrigel/crypt mix was placed in the center well of a 12-well plate. After 30 minutes of polymerization, $650 \mu \mathrm{L}$ of the mini gut medium was overlain $(31,51)$. The mini gut medium (advanced DMEM/F12 supplemented with HEPES, Lglutamine, N2 and B27) was added to the culture, along with R-Spondin, Noggin, and EGF. The medium was changed every 2-3 days. For passage, the organoids were removed from the Matrigel and broken up mechanically by passing them through a syringe and needle (27 G, BD Biosciences, San Jose, CA), and then, they were transferred to fresh Matrigel. The passage was performed every $7-10$ days with a 1:4 split ratio.

Bacterial colonization. Polarized human epithelial cells were grown in DMEM with 10\% FBS. At $90-100 \%$ confluence, the cells were colonized with an equal number of the indicated Salmonella Enteritidis strain for 30 minutes, washed with Hank's balanced salt solution (HBSS), and incubated in DMEM containing gentamicin $(100 \mu \mathrm{g} / \mathrm{ml})$ for 30 minutes. The first 30 minutes of the incubation allowed the bacteria to contact the epithelial cell surface and inject the effectors into the host cells $(52,53)$. After extensive HBSS washing, the extracellular bacteria were washed away. The incubation with 
gentamicin inhibited the bacterial growth (54). At the indicated times, post-colonization, the cells samples were harvested for the analysis.

The organoids (6 days after passage) were colonized with the indicated Salmonella Enteritidis strain for 30 minutes, washed with HBSS, and incubated in mini gut media containing gentamicin $(500 \mathrm{mg} / \mathrm{mL})$ for the indicated times, as described in our previous studies (31). After extensive HBSS washing, the extracellular bacteria were washed away. The incubation with gentamicin inhibited the growth of the bacteria. Samples were collected for a Western blot analysis or immunofluorescence after the organoids were colonized with Salmonella for 30 minutes and were then incubated in medium with gentamicin for 1 hour.

Cell treatment with the JNK inhibitor SP600125.The JNK inhibitor SP600125 (50 mM, EMD Biosciences, San Diego, CA, USA) was added directly to the culture medium one hour before Salmonella treatment. The HCT116 cells were pretreated with SP600125 and were incubated with the indicated Salmonella for 30 minutes, washed 3 times in HBSS, incubated in DMEM containing $100 \mu \mathrm{g} / \mathrm{ml}$ gentamicin and $50 \mu \mathrm{M}$ SP600125 for 30 minutes, and harvested. The protein levels were determined by Western blotting.

Lysotracker staining. Lysotracker staining was performed following the manufacturer's protocol (Life technologies). The HCT116 cells were grown in the Lab-Tek Chambered Coverglass System (154526, Thermo Scientific, Rockford, IL, USA), and the cells were then incubated with 100 nM LysoTracker Deep Red Probe (L12492, Life technologies, Eugene, OR, USA) in cell growth medium at $37^{\circ} \mathrm{C}$ for 60 minutes. After washing with HBBS, the cells were incubated with the indicated Salmonella for 30 minutes, washed 3 times in HBSS, incubated in DMEM containing $100 \mu \mathrm{g} / \mathrm{ml}$ gentamicin for 30 minutes, and 
the cells were detected by fluorescence microscopy (ECLIPSE E600, Nikon Instruments, Inc., Melville, NY, USA.).

Streptomycin pre-treated Salmonella mouse model. Water and food were withdrawn 4 hours before an oral gavage with $7.5 \mathrm{mg} / \mathrm{mouse}$ streptomycin. Afterward, the animals were supplied with water and food. Twenty hours after the streptomycin treatment, water and food were once again withdrawn for 4 hours before the mice were infected with $1.0 \times 10^{8} \mathrm{CFU}$ of Salmonella (100 $\mu \mathrm{l}$ bacterial suspension in HBSS) or treated with sterile HBSS (control) by oral gavage, as previously described (32). At the indicated times postinfection, the mice were sacrificed, and the intestinal tissue samples were removed for the analysis.

Immunoblotting and antibodies. Mouse epithelial cells were scraped and lysed in lysis buffer (1\% Triton $\mathrm{X}-100,150 \mathrm{mM} \mathrm{NaCl}, 10 \mathrm{mM}$ Tris pH 7.4, 1 mM EDTA, 1 mM EGTA $\mathrm{pH}$ 8.0, $0.2 \mathrm{mM}$ sodium orthovanadate, and protease inhibitor cocktail), and the protein concentration was measured using Protein Assay Kits (Bio-Rad, Hercules, CA, USA) (52). The cultured cells were rinsed twice in ice-cold HBSS and were lysed in protein loading buffer (50 mM Tris $\mathrm{pH} 6.8,100 \mathrm{mM}$ dithiothreitol, 2\% SDS, 0.1\% bromophenol blue, and $10 \%$ glycerol), and the remaining cells were scraped off the dish and sonicated to shear the DNA and reduce the sample viscosity. The organoid cells were rinsed three times in ice-cold HBSS and were then suspended in ice-cold HBSS. The organoid cells were then spun down at $900 \mathrm{rpm}$ for 10 minutes at $4^{\circ} \mathrm{C}$. Next, using a pipette to aspirate the PBS at the top, the organoid cells were lysed in lysis buffer and were then sonicated (31). The protein concentration was then measured. Equal amounts of protein were separated by SDS-polyacrylamide gel electrophoresis and were transferred to nitrocellulose membranes. The nonspecific sites were blocked with $5 \%$ bovine serum 
albumin (BSA) in TBST (50 mM Tris, $150 \mathrm{mM} \mathrm{NaCl}$, and $0.05 \%$ Tween 20 adjusted to $\mathrm{pH} 7.6$ with $\mathrm{HCl}$ ), and the membranes were then incubated with dilutions of the primary antibodies as recommended by the manufacturers. The primary antibodies included the following: anti-p62 (1:1,000, AP2183B, ABGENT, San Diego, CA,USA); anti-LC3B $(1: 1,000, \quad 2775), \quad$ anti-SAPK/JNK $\quad(1: 1,000, \quad 9258), \quad$ anti-phospho-SAPK/JNK (Thr183/Tyr185, 1:1,000, 9251), anti-c-jun (60A8, 1:1,000, 9165), anti-phospho-c-jun (S63, 1:1,000, 9261) (Cell Signaling, Beverly, MA, USA); anti-BECN1/Beclin-1 (1:1,000, SC-10086), anti-C-myc (PE10, 1:1,000, SC-40), anti-HA-probe (F-7, 1:1,000, SC-7392) (Santa Cruz Biotechnology, Inc., Santa Cruz, CA, USA); anti- $\beta$-actin (1:2,000, A5441, Sigma-Aldrich, Milwaukee, WI, USA); anti-ubiquitin (1:1,000, UG9511, ENZO, Farmingdale, NY, USA); and anti-AvrA (1:1,000, custom-made, as reported in our previous studies (55)). The membranes were washed and incubated with an HRPconjugated secondary antibody (anti-mouse, 1:5,000, 31430; anti-rabbit, 1:5,000, 31460; anti-goat, 1:5,000, R-21459, Invitrogen, Grand Island, NY, USA). The membranes were then washed again, treated with the ECL Western Blotting Substrate (Thermo Scientific, Rockford, IL, USA) and visualized on X-ray film. The membranes that were sequentially probed with more than one antibody were stripped in stripping buffer (Thermo Scientific, Rockford, IL, USA) before re-probing.

Immunoprecipitation. The cells were rinsed twice in ice-cold HBSS and were lysed in ice-cold immunoprecipitation buffer (1\% Triton X-100, $150 \mathrm{mmol} / \mathrm{L} \mathrm{NaCl}, 10 \mathrm{mmol} / \mathrm{L}$ Tris, $\mathrm{pH} 7.4,1 \mathrm{mmol} / \mathrm{L}$ EDTA, $1 \mathrm{mmol} / \mathrm{L}$ ethylene glycol bis ( $\beta$-aminoethyl ether)- $N, N, N^{\prime}, N^{\prime}-$ tetraacetic acid, $\mathrm{pH} 8.0,0.2 \mathrm{mmol} / \mathrm{L}$ sodium orthovanadate, and protease inhibitor cocktail (Roche Diagnostics, Basel, Switzerland)). The samples were prepared as previously described(56). The blots were probed with anti-HA-probe (F-7, 1:1,000, SC- 
7392, Santa Cruz Biotechnology, Inc., Santa Cruz, CA, USA) and anti-c-myc (PE10, SC40, Santa Cruz Biotechnology, Inc., Santa Cruz, CA, USA) antibodies.

Immunofluorescence. The ileal tissues from the distal portion of the ileum were freshly isolated and paraffin-embedded after fixation with $10 \%$ neutral buffered formalin. Immunofluorescence was performed on the paraffinembedded sections $(5 \mu \mathrm{m})$. After preparation of the slides, as described previously (53), the tissue samples were incubated with the indicated primary antibody, anti-lysozyme (1:100, sc27958, Santa Cruz Biotechnology, Inc., Santa Cruz, CA, USA), at $4^{\circ} \mathrm{C}$ overnight. The samples were then incubated with the sheep anti-goat Alexa Fluor 594 (A11058, Life Technologies, Grand Island, NY, USA) and DAPI (D1306, Life Technologies, Grand Island, NY, USA) for 1 hour at room temperature. The tissues were mounted with SlowFade (s2828, Life technologies, Grand Island, NY, USA), followed by a coverslip, and the edges were sealed to prevent drying. The specimens were examined with a Zeiss laser scanning microscope 710 (Carl Zeiss, Inc., Oberkochen, Germany).

Paneth cell staining and counting. The Paneth cells in the mouse ileal tissue were counted after the anti-lysozyme immunofluorescence staining, according to our previous study(35). The patterns of the lysozyme expression in the Paneth cells were classified into four categories as follows: normal (D0); disordered (D1); depleted (D2) and diffuse (D3), according to previously published methods (36).

AP-1 Transcriptional Activity Assay. The cells were transiently transfected with $1 \mu \mathrm{g}$ of pGL3-AP1 plasmid using the Lipofectamine 3000 transfection kit, according to the 
manufacturer's instructions (Invitrogen, Carlsbad, CA). The pRL-TK vector was used as an internal control reporter. After 24 hours post transfection, the cells were colonized with equal numbers of bacteria for 30 minutes, washed, and incubated in DMEM containing gentamicin $(100 \mu \mathrm{g} / \mathrm{ml})$ for 30 minutes. The luciferase activity was monitored using the dual luciferase assay system (Promega).

Statistical analysis. Data are expressed as the mean \pm SE. All statistical tests were 2sided. The $p$ values $<0.05$ were considered statistically significant. The differences between two samples were analyzed using Student's $t$-test; the differences among three or more groups were analyzed using one-way ANOVA. The Tukey's method was used to adjust multiple comparisons to ensure results accurately. All statistical analyses were performed by GraphPad Prism 5(GraphPad Software, La Jolla, CA) or SAS version 9.4 (SAS Institute, Inc., Cary, NC, USA). 


\section{Author contribution}

Y. J., Z. L., Y. Z., C. M. and R. L.: data acquisition, analysis and interpretation, and drafting of the manuscript. Y. J., Y.Z., and J. S.: wrote the main manuscript text and prepared the figures. Y. X.: statistical analysis and drafting of the manuscript. Z. P., X. J. and X. X.: technical or material support and drafting of the manuscript. J. S.: study concept and design, critical revision of the manuscript for important intellectual content, and study supervision. All the authors reviewed the manuscript.

\section{Disclosures}

The authors have no financial conflicts of interest. 


\section{REFERENCES}

1. Patrick ME, Adcock PM, Gomez TM, Altekruse SF, Holland BH, Tauxe RV, Swerdlow DL. 2004. Salmonella enteritidis infections, United States, 1985-1999. Emerg Infect Dis 10:1-7.

2. Wright AP, Richardson L, Mahon BE, Rothenberg R, Cole DJ. 2016. The rise and decline in Salmonella enterica serovar Enteritidis outbreaks attributed to eggcontaining foods in the United States, 1973-2009. Epidemiol Infect 144:810-9.

3. Scallan E, Hoekstra RM, Angulo FJ, Tauxe RV, Widdowson MA, Roy SL, Jones JL, Griffin PM. 2011. Foodborne illness acquired in the United States--major pathogens. Emerg Infect Dis 17:7-15.

4. Majowicz SE, Musto J, Scallan E, Angulo FJ, Kirk M, O'Brien SJ, Jones TF, Fazil A, Hoekstra RM, International Collaboration on Enteric Disease 'Burden of Illness S. 2010. The global burden of nontyphoidal Salmonella gastroenteritis. Clin Infect Dis 50:882-9.

5. Levine B, Mizushima N, Virgin HW. 2011. Autophagy in immunity and inflammation. Nature 469:323-35.

6. Steele-Mortimer O. 2008. The Salmonella-containing vacuole: moving with the times. Curr Opin Microbiol 11:38-45.

7. Buchmeier NA, Heffron F. 1991. Inhibition of macrophage phagosome-lysosome fusion by Salmonella typhimurium. Infect Immun 59:2232-8.

8. Knodler LA, Finlay BB. 2001. Salmonella and apoptosis: to live or let die? Microbes Infect 3:1321-6.

9. Jones RM, Wu H, Wentworth C, Luo L, Collier-Hyams L, Neish AS. 2008. Salmonella AvrA Coordinates Suppression of Host Immune and Apoptotic Defenses via JNK Pathway Blockade. Cell Host Microbe 3:233-44.

10. Owen KA, Meyer CB, Bouton AH, Casanova JE. 2014. Activation of focal adhesion kinase by Salmonella suppresses autophagy via an Akt/mTOR signaling pathway and promotes bacterial survival in macrophages. PLoS Pathog 10:e1004159.

11. Ganesan R, Hos NJ, Gutierrez S, Fischer J, Stepek JM, Daglidu E, Kronke M, Robinson N. 2017. Salmonella Typhimurium disrupts Sirt1/AMPK checkpoint control of mTOR to impair autophagy. PLoS Pathog 13:e1006227.

12. Jiao Y, Sun J. 2019. Bacterial Manipulation of Autophagic Responses in Infection and Inflammation. Frontiers in Immunology 10.

13. Randow F, Munz C. 2012. Autophagy in the regulation of pathogen replication and adaptive immunity. Trends Immunol 33:475-87.

14. Li S, Wandel MP, Li F, Liu Z, He C, Wu J, Shi Y, Randow F. 2013. Sterical hindrance promotes selectivity of the autophagy cargo receptor NDP52 for the danger receptor galectin-8 in antibacterial autophagy. Sci Signal 6:ra9.

15. Deretic V, Levine B. 2018. Autophagy balances inflammation in innate immunity. Autophagy 14:243-251.

16. Gomes LC, Dikic I. 2014. Autophagy in antimicrobial immunity. Mol Cell 54:22433.

17. Mizushima N, Yoshimori T, Ohsumi Y. 2011. The role of Atg proteins in autophagosome formation. Annu Rev Cell Dev Biol 27:107-32.

18. Kang R, Zeh HJ, Lotze MT, Tang D. 2011. The Beclin 1 network regulates autophagy and apoptosis. Cell Death Differ 18:571-80.

19. Liang XH, Jackson S, Seaman M, Brown K, Kempkes B, Hibshoosh H, Levine B. 1999. Induction of autophagy and inhibition of tumorigenesis by beclin 1. Nature 402:672-6. 
20. Dalbey RE, Kuhn A. 2012. Protein traffic in Gram-negative bacteria--how exported and secreted proteins find their way. FEMS Microbiol Rev 36:1023-45.

21. Ellermeier JR, Slauch JM. 2007. Adaptation to the host environment: regulation of the SPI1 type III secretion system in Salmonella enterica serovar Typhimurium. Curr Opin Microbiol 10:24-9.

22. Figueira R, Holden DW. 2012. Functions of the Salmonella pathogenicity island 2 (SPI-2) type III secretion system effectors. Microbiology 158:1147-61.

23. Petersen E, Mills E, Miller SI. 2019. Cyclic-di-GMP regulation promotes survival of a slow-replicating subpopulation of intracellular Salmonella Typhimurium. Proc Natl Acad Sci U S A 116:6335-6340.

24. Ye Z, Petrof EO, Boone D, Claud EC, Sun J. 2007. Salmonella effector AvrA regulation of colonic epithelial cell inflammation by deubiquitination. Am J Pathol $171: 882-92$.

25. Collier-Hyams LS, Zeng H, Sun J, Tomlinson AD, Bao ZQ, Chen H, Madara JL, Orth K, Neish AS. 2002. Cutting edge: Salmonella AvrA effector inhibits the key proinflammatory, anti-apoptotic NF-kappa B pathway. J Immunol 169:2846-50.

26. Du F, Galan JE. 2009. Selective inhibition of type III secretion activated signaling by the Salmonella effector AvrA. PLoS Pathog 5:e1000595.

27. Naydenov NG, Hopkins AM, Ivanov Al. 2009. C-Jun N-terminal kinase mediates disassembly of apical junctions in model intestinal epithelia. Cell Cycle 8:2110-21.

28. Lin Z, Zhang YG, Xia Y, Xu X, Jiao X, Sun J. 2016. Salmonella enteritidis Effector AvrA Stabilizes Intestinal Tight Junctions via the JNK Pathway. J Biol Chem 291:26837-26849.

29. Jiang P, Mizushima N. 2015. LC3- and p62-based biochemical methods for the analysis of autophagy progression in mammalian cells. Methods 75:13-8.

30. Li DD, Wang LL, Deng R, Tang J, Shen Y, Guo JF, Wang Y, Xia LP, Feng GK, Liu QQ, Huang WL, Zeng YX, Zhu XF. 2009. The pivotal role of c-Jun NH2terminal kinase-mediated Beclin 1 expression during anticancer agents-induced autophagy in cancer cells. Oncogene 28:886-98.

31. Zhang YG, Wu S, Xia Y, Sun J. 2014. Salmonella-infected crypt-derived intestinal organoid culture system for host-bacterial interactions. Physiol Rep 2.

32. Barthel M, Hapfelmeier S, Quintanilla-Martinez L, Kremer M, Rohde M, Hogardt M, Pfeffer K, Russmann H, Hardt WD. 2003. Pretreatment of mice with streptomycin provides a Salmonella enterica serovar Typhimurium colitis model that allows analysis of both pathogen and host. Infect Immun 71:2839-58.

33. Vijay-Kumar M, Wu H, Jones R, Grant G, Babbin B, King TP, Kelly D, Gewirtz AT, Neish AS. 2006. Flagellin suppresses epithelial apoptosis and limits disease during enteric infection. Am J Pathol 169:1686-700.

34. Deretic V, Master S, Singh S. 2008. Autophagy gives a nod and a wink to the inflammasome and Paneth cells in Crohn's disease. Dev Cell 15:641-2.

35. Wu S, Zhang YG, Lu R, Xia Y, Zhou D, Petrof EO, Claud EC, Chen D, Chang EB, Carmeliet G, Sun J. 2015. Intestinal epithelial vitamin D receptor deletion leads to defective autophagy in colitis. Gut 64:1082-94.

36. Cadwell K, Liu JY, Brown SL, Miyoshi H, Loh J, Lennerz JK, Kishi C, Kc W, Carrero JA, Hunt S, Stone CD, Brunt EM, Xavier RJ, Sleckman BP, Li E, Mizushima N, Stappenbeck TS, Virgin HWt. 2008. A key role for autophagy and the autophagy gene Atg16l1 in mouse and human intestinal Paneth cells. Nature 456:259-63.

37. Benjamin JL, Sumpter R, Jr., Levine B, Hooper LV. 2013. Intestinal epithelial autophagy is essential for host defense against invasive bacteria. Cell Host Microbe 13:723-34. 
38. Wang L, Yan J, Niu H, Huang R, Wu S. 2018. Autophagy and Ubiquitination in Salmonella Infection and the Related Inflammatory Responses. Front Cell Infect Microbiol 8:78.

39. Schulthess J, Pandey S, Capitani M, Rue-Albrecht KC, Arnold I, Franchini F, Chomka A, llott NE, Johnston DGW, Pires E, McCullagh J, Sansom SN, Arancibia-Carcamo CV, Uhlig HH, Powrie F. 2019. The Short Chain Fatty Acid Butyrate Imprints an Antimicrobial Program in Macrophages. Immunity 50:432445 e7.

40. Saleh S, Van Puyvelde S, Staes A, Timmerman E, Barbe B, Jacobs J, Gevaert K, Deborggraeve S. 2019. Salmonella Typhi, Paratyphi A, Enteritidis and

Typhimurium core proteomes reveal differentially expressed proteins linked to the cell surface and pathogenicity. PLoS Negl Trop Dis 13:e0007416.

41. Khan SB, Khan MA, Ahmad I, Ur Rehman T, Ullah S, Dad R, Sultan A, Memon AM. 2019. Phentotypic, gentotypic antimicrobial resistance and pathogenicity of Salmonella enterica serovars Typimurium and Enteriditis in poultry and poultry products. Microb Pathog 129:118-124.

42. Lamas A, Miranda JM, Regal P, Vazquez B, Franco CM, Cepeda A. 2018. A comprehensive review of non-enterica subspecies of Salmonella enterica. Microbiol Res 206:60-73.

43. Xia P, Wang S, Du Y, Zhao Z, Shi L, Sun L, Huang G, Ye B, Li C, Dai Z, Hou N, Cheng X, Sun Q, Li L, Yang X, Fan Z. 2013. WASH inhibits autophagy through suppression of Beclin 1 ubiquitination. EMBO J 32:2685-96.

44. Zhang YG, Zhu X, Lu R, Messer JS, Xia Y, Chang EB, Sun J. 2019. Intestinal epithelial HMGB1 inhibits bacterial infection via STAT3 regulation of autophagy. Autophagy doi:10.1080/15548627.2019.1596485:1-19.

45. Koslowski MJ, Beisner J, Stange EF, Wehkamp J. 2010. Innate antimicrobial host defense in small intestinal Crohn's disease. Int J Med Microbiol 300:34-40.

46. Wehkamp J, Wang G, Kubler I, Nuding S, Gregorieff A, Schnabel A, Kays RJ, Fellermann K, Burk O, Schwab M, Clevers H, Bevins CL, Stange EF. 2007. The Paneth cell alpha-defensin deficiency of ileal Crohn's disease is linked to Wnt/Tcf-4. J Immunol 179:3109-18.

47. Menard S, Forster V, Lotz M, Gutle D, Duerr CU, Gallo RL, Henriques-Normark B, Putsep K, Andersson M, Glocker EO, Hornef MW. 2008. Developmental switch of intestinal antimicrobial peptide expression. J Exp Med 205:183-93.

48. Wang D, Peregrina K, Dhima E, Lin EY, Mariadason JM, Augenlicht LH. 2011. Paneth cell marker expression in intestinal villi and colon crypts characterizes dietary induced risk for mouse sporadic intestinal cancer. Proc Natl Acad Sci U S A 108:10272-7.

49. Bel S, Pendse M, Wang Y, Li Y, Ruhn KA, Hassell B, Leal T, Winter SE, Xavier RJ, Hooper LV. 2017. Paneth cells secrete lysozyme via secretory autophagy during bacterial infection of the intestine. Science 357:1047-1052.

50. McCormick BA, Colgan SP, Delp-Archer C, Miller SI, Madara JL. 1993. Salmonella typhimurium attachment to human intestinal epithelial monolayers: transcellular signalling to subepithelial neutrophils. J Cell Biol 123:895-907.

51. Wang N, Zhang H, Zhang BQ, Liu W, Zhang Z, Qiao M, Zhang H, Deng F, Wu N, Chen X, Wen S, Zhang J, Liao Z, Zhang Q, Yan Z, Yin L, Ye J, Deng Y, Luu HH, Haydon RC, Liang H, He TC. 2014. Adenovirus-mediated efficient gene transfer into cultured three-dimensional organoids. PLoS One 9:e93608.

52. Wu S, Liao AP, Xia Y, Li YC, Li JD, Sartor RB, Sun J. 2010. Vitamin D receptor negatively regulates bacterial-stimulated NF-kappaB activity in intestine. Am J Pathol 177:686-97. 
53. Lu R, Wu S, Liu X, Xia Y, Zhang YG, Sun J. 2010. Chronic effects of a Salmonella type III secretion effector protein AvrA in vivo. PLoS One 5:e10505.

54. Sun J, Hobert ME, Rao AS, Neish AS, Madara JL. 2004. Bacterial activation of beta-catenin signaling in human epithelia. Am J Physiol Gastrointest Liver Physiol 287:G220-7.

55. Boyle EC, Brown NF, Finlay BB. 2006. Salmonella enterica serovar Typhimurium effectors SopB, SopE, SopE2 and SipA disrupt tight junction structure and function. Cell Microbiol 8:1946-57.

56. Sun J, Hobert ME, Duan Y, Rao AS, He TC, Chang EB, Madara JL. 2005. Crosstalk between NF-kappaB and beta-catenin pathways in bacterial-colonized intestinal epithelial cells. Am J Physiol Gastrointest Liver Physiol 289:G129-37.

57. Sun Q, Fan W, Chen K, Ding X, Chen S, Zhong Q. 2008. Identification of Barkor as a mammalian autophagy-specific factor for Beclin 1 and class III phosphatidylinositol 3-kinase. Proc Natl Acad Sci U S A 105:19211-6. 


\section{Abbreviations}

AvrA C186A mutation

BSA

CFU

DMEM

EDTA

FBS

HBSS

IP

JNK

LB

Salmonella Enteritidis, S.

Enteritidis, S.E

Salmonella Typhimurium

S.E-WT

S.E-AvrA

S.E-AvrA ${ }^{+}$

SPI-1

T3SS

ub-Beclin-1 mutated at the key cysteine required for AvrA activity

bovine serum albumin

colony forming units

Dulbecco's modified Eagle's medium

ethylenediamine tetraacetic acid

fetal bovine serum

Hank's balanced salt solution

immunoprecipitated

c-Jun N-terminal kinase

Luria-Bertani

Salmonella enterica serovar Typhimurium

Salmonella Enteritidis wild-type strain C50336

Salmonella Enteritidis AvrA deletion mutant

plasmid mediated complementary strain S.E-AvrA-/pAvrA ${ }^{+}$

Salmonella pathogenicity island 1

type III secretion system

ubiquitinated Beclin-1 
Table I. Bacterial strains and plasmids used in this study

\begin{tabular}{|c|c|c|}
\hline Strains/Plasmids & Characteristics & References \\
\hline \multicolumn{3}{|l|}{ Strains } \\
\hline S.E-WT & $\begin{array}{l}\text { Wild-type Salmonella Enteritidis } \\
\text { CMCC(B)50336 }\end{array}$ & NICPBP, China \\
\hline S.E-AvrA ${ }^{-}$ & C50336 AvrA-deficient mutant & Ref. (28) \\
\hline S.E-AvrA ${ }^{+}$ & $\begin{array}{l}\text { C50336 AvrA-deficient mutant carrying } \\
\text { pBR322-AvrA }\left(\mathrm{Amp}^{r}\right)\end{array}$ & Ref. (28) \\
\hline \multicolumn{3}{|l|}{ Plasmids } \\
\hline pCMV-c-myc-AvrA & $\begin{array}{l}\text { Plasmid of S.E full-length AvrA gene, AvrA } \\
\text { WT plasmid, c-myc tag }\end{array}$ & Ref. (24) \\
\hline pCMV-c-myc- & Plasmid of S.E full-length AvrA gene with one- & Ref. (24) \\
\hline $\operatorname{AvrA}(\mathrm{C} 186 \mathrm{~A})$ & $\begin{array}{l}\text { point mutant C186A, AvrA C186A mutant } \\
\text { plasmid, c-myc tag }\end{array}$ & \\
\hline pcDNA4-HA-Beclin-1 & $\begin{array}{l}\text { Plasmid of human BECN1 gene, Beclin-1 WT } \\
\text { plasmid, HA tag }\end{array}$ & Ref. (57) \\
\hline pGL3-AP1 & $\begin{array}{l}\text { Plasmid of } A P 1 \text { promoter gene, fluorescein } \\
\text { tag }\end{array}$ & Ref. (24) \\
\hline
\end{tabular}




\section{FIGURE LEGENDS}

Figure 1. Salmonella Enteritidis AvrA inhibits autophagy in cell models.

AvrA-regulated expression levels of autophagy related proteins. (A) The indicated HCT116 cell lines were infected with S.E WT, S.E-AvrA ${ }^{-}$and S.E-AvrA+ strains (MOI:1:1, 1h incubation before harvested, $n=4$ ) as shown and analyzed for protein expression by immunoblotting. The immunoblotting of P62/LC3 was used to track the expression of P62 and the conversion of LC3 I into LC3 II for autophagic activity in the HCT116 cells after infection with the different S.E. The relative density of P62 (B) and LC3 II/LC3 I (C) was determined using Quantity One 4.6.2 software (Bio-Rad, Hercules, CA, USA). $n=4$, ${ }^{* *}$ adjusted $P<0.01,{ }^{* * *}$ adjusted $P<0.001$ by ANOVA test. (D) HCT116 cell lines were incubated with 100 nM LysoTracker Deep Red Probe, then infected with S.E WT, S.EAvrA- and S.E-AvrA+ strains (MOI:1:1, $1 \mathrm{~h}$ incubation before microscopic examination) to check the lysosomes staining. The immunofluorescence indicated that the HCT116 cells, pre-treated with LysoTracker, showed more lysosomes in the cells infected with the S.EAvrA bacteria compared with the cells infected by the AvrA present strains. (E) Quantification of the number of lysotracker positive vesicles. The data are reported as the mean \pm SE from three independent experiments, and a total of 100 cells per condition were analyzed. $\mathrm{n}=100,{ }^{* *}$ adjusted $P<0.01$, ${ }^{* *}$ adjusted $P<0.001$ by ANOVA test. (F) The numbers of internalized Salmonella in human epithelial cells colonized with wild-type Salmonella Enteritidis or AvrA mutant or AvrA-complemented strains. Human epithelial cells were grown on an insert, colonized with an equal number of the indicated bacteria for 30 min, after washed with HBSS, cells were incubated in DMEM containing gentamicin $(100 \mu \mathrm{g} / \mathrm{ml})$ for $30 \mathrm{~min}$, and the number of internalized Salmonella (Salmonella invasion) was then determined. Data are reported 
as the mean \pm SE from six independent experiments, *adjusted $P<0.05$, **adjusted $P<0.05$ by ANOVA test.

Figure 2. AvrA changes Beclin-1 protein levels and interacts with Beclin-1 in HCT116 cells.

AvrA changes Beclin-1 protein levels and interacts with Beclin-1 in HCT116 cells. (A) The Western blot shows the expression of Beclin-1 in the HCT116 cells after colonization with wild-type Salmonella Enteritidis or AvrA mutant or AvrA-complemented strains (MOI:1:1, $1 \mathrm{~h}$ incubation before harvested, $\mathrm{n}=4$ ). The relative density of Beclin-1 (B) was determined using Quantity One 4.6.2 software (Bio-Rad, Hercules, CA, USA). $\mathrm{n}=4$, *adjusted $P<0.05$ by ANOVA test. (C) The Western blot shows the expression of Beclin-1 in the HCT116 cells after transfection with the AvrA wild-type and AvrA mutant plasmids (200 ng/ $\mu$ l, 24h incubation, $n=5)$. The relative density of Beclin-1 d was determined using Quantity One 4.6.2 software (Bio-Rad, Hercules, CA, USA). n=5, *adjusted $P<0.05$, **adjusted $P<0.01$ by ANOVA test. (E) The HCT116 cells were cotransfected with the AvrA WT plasmid (c-myc tag) and the Beclin-1 WT plasmid (HAtag) (200 ng/ $\mu \mathrm{l}, 24 \mathrm{~h}$ incubation, $\mathrm{n}=4)$. At the indicated times, immunoprecipitation was performed with an anti-c-myc mouse monoclonal antibody. Pre-immune mouse lgG was used as a negative control. VPS34 was used as a positive control. The Western blot analyses of the pre-immunoprecipitation (Input) and immunoprecipitated samples (IP) were performed with an anti-c-myc mouse monoclonal antibody or with an anti-HA mouse monoclonal antibody. These results shown are representative of three independent experiments.

Figure 3. AvrA inhibits the JNK/C-jun/AP-1 signaling pathway to decrease Beclin-1 in HCT116 cells. 
AvrA inhibited the JNK pathway and decreased Beclin-1 in HCT116 cells, and the effect of AvrA on Beclin-1 expression was abolished by the JNK inhibitor SP600125. (A) The Western blot shows a change in the JNK pathway markers and Beclin-1 in the cells treated with the JNK inhibitor SP600125 (50 $\mu \mathrm{M}, 30 \mathrm{~min})$ and those infected with the different S.E strains (MOI:1:1, $1 \mathrm{~h}$ incubation before harvested, $\mathrm{n}=4$ ), These results shown are representative of four independent experiments. (B) The luciferase reporter assay shows a change in AP-1 transcription in the cells treated with the JNK inhibitor SP600125 and in those infected with the different S.E strains (MOI:1:1, $1 \mathrm{~h}$ incubation before harvested, $\mathrm{n}=6$ ). ${ }^{*}$ adjusted $P<0.05$ by ANOVA test.

Figure 4. The AvrA C186A mutant plasmid abolishes the regulation of exogenous

\section{Beclin-1.}

The HCT116 cells were transfected with the indicated plasmids $(200 \mathrm{ng} / \mu \mathrm{l}, 24 \mathrm{~h}$ incubation, $n=4)$. At the indicated times, the changes in the target proteins were measured. (A) The Western blot shows the expression of Beclin-1 in the HCT116 cells after transfection with the indicated plasmids. The relative density of Beclin-1 (B) was determined using Quantity One 4.6.2 software (Bio-Rad, Hercules, CA, USA). n=4, ${ }^{\star} P<$ 0.05 by student's t-test. (C) The Western blot shows the change in the JNK pathway markers and Beclin-1 in the HCT116 cells after transfection with the AvrA wild-type and AvrA mutant plasmids. These results shown are representative of four independent experiments.

\section{Figure 5. Salmonella Enteritidis AvrA changes the levels of Beclin-1 in mouse intestinal organoids.}

Salmonella Enteritidis infection and invasion in the mouse organoids. (A) The Western blot shows the expression of Beclin-1, P62, LC3 and the JNK pathway markers in the 
organoids after infection with wild-type Salmonella Enteritidis or AvrA mutant or AvrAcomplemented strains (MOI:1:1, 1.5h incubation before harvested, $n=3$ ). The relative density of Beclin-1 (B), P62 (C) and LC3 II/LC3 I (D) was determined using Quantity One 4.6.2 software (Bio-Rad, Hercules, CA, USA). $\mathrm{n}=3$, *adjusted $P<0.05$, **adjusted $P<0.01$, " unadjusted $P<0.05$ by ANOVA test. (E) The representative images of the immunostaining of $\mathrm{P} 62$ in the organoids after infection with wild-type Salmonella Enteritidis or AvrA mutant or AvrA-complemented strains (MOI:1:1, 1.5h incubation).

Figure 6. AvrA changes the levels of Beclin-1 and affects the function of Paneth cell granules of the ileal tissues in a mouse model.

Wild-type Salmonella Enteritidis, AvrA mutant or AvrA-complemented strains were used to infect C57BL/6 mouse models $\left(1.0 \times 10^{8} \mathrm{CFU}\right.$ per mouse, i.g., $\left.\mathrm{n}=6\right)$. At $8 \mathrm{~h}$ postinfection, the ileal tissue was harvested for immunoblotting and immunofluorescence staining. (A) Western blot shows the expression of Beclin-1, P62, LC3 and the JNK pathway markers in the ileal tissue after infection with the different S.E strains. The relative density of Beclin-1 (B), P62 (C) and LC3 II/LC3 I (D) was determined using Quantity One 4.6.2 software (Bio-Rad, Hercules, CA, USA). n=5-6, *adjusted $P<0.05$, **adjusted $P<0.01$ by ANOVA test. (E) The representative images of the indirect immunofluorescence of the sections stained for lysozymes (red) in the ileal crypts of the C57BL/6 mice following infected with wild-type Salmonella Enteritidis or AvrA mutant strains. (F) The percentage of Paneth cells displaying a normal (D0) and abnormal (D1 to D3) pattern of lysozyme expression. $\mathrm{n}=5-6$, *adjusted $P<0.05$, **adjusted $P<0.01$, ***adjusted $P<0.001$ by ANOVA test.

Figure 7. Working model of AvrA inhibition of Beclin-1-dependent autophagy. Salmonella Enteritidis AvrA inhibits the autophagic response by decreasing Beclin-1 
protein. At the molecular level, AvrA interacts with Beclin-1. This process occurs through the inhibition of the JNK signaling pathway. At the cellular level, AvrA affects the function of Paneth cell granules by inhibiting autophagy. 
Fig. 1

A

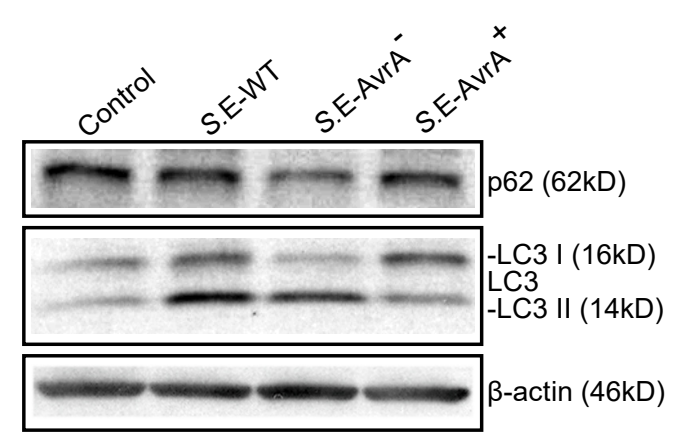

B

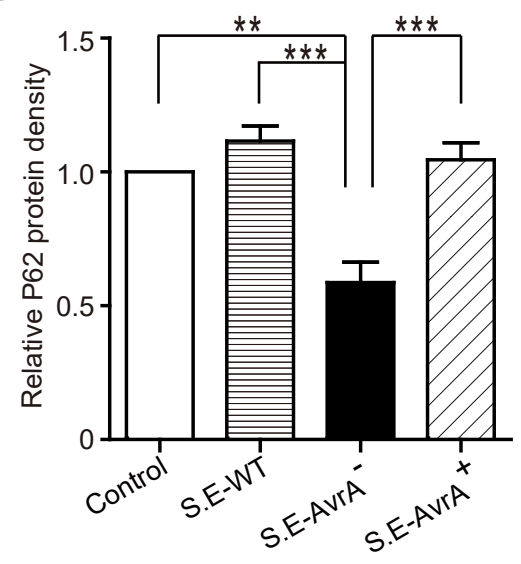

C

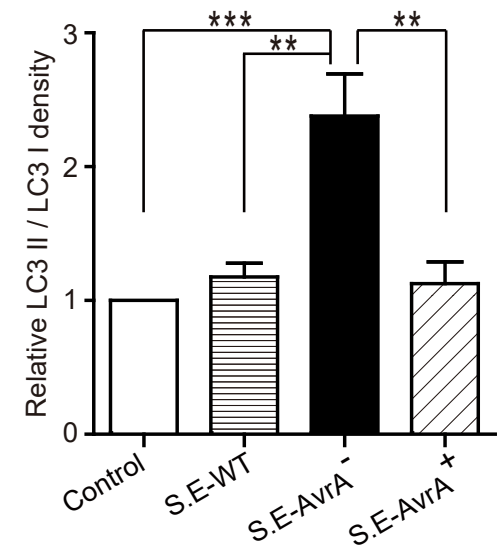

$\mathrm{D}$

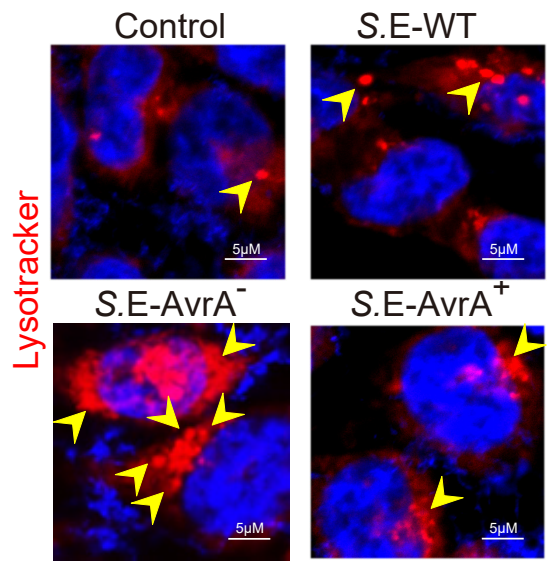

E

$\mathrm{F}$
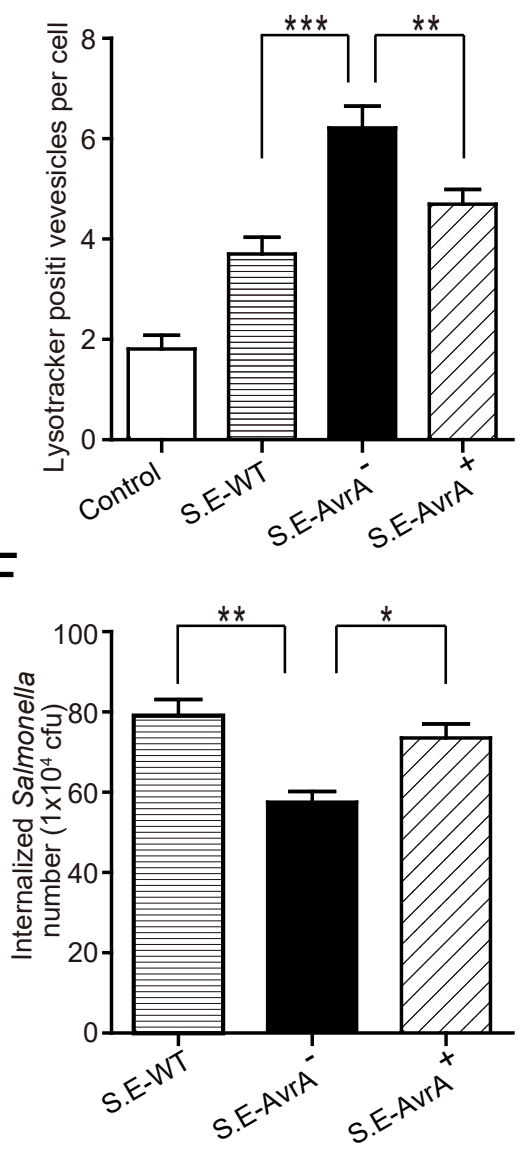
Fig. 2

A

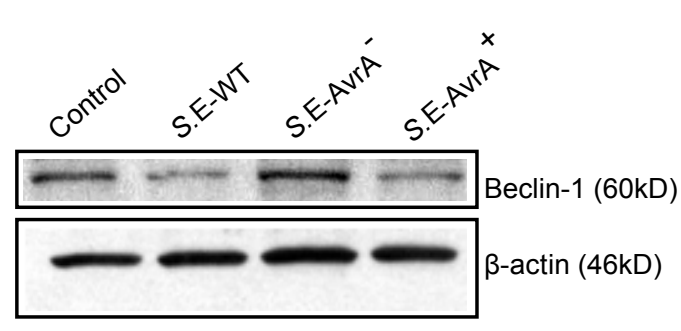

B

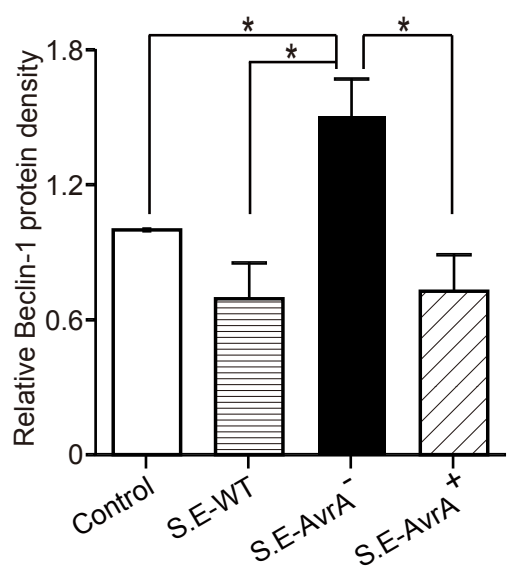

$E$

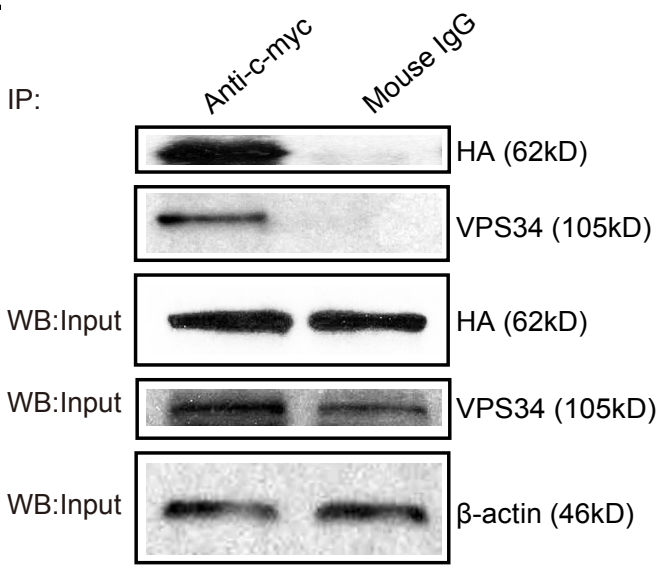

C

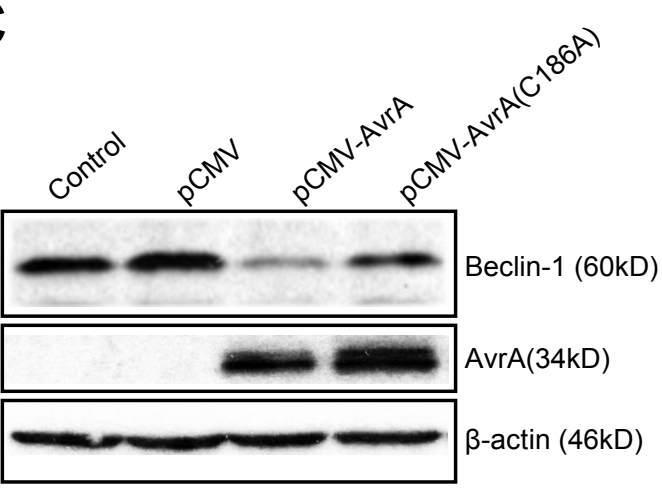

$\mathrm{D}$

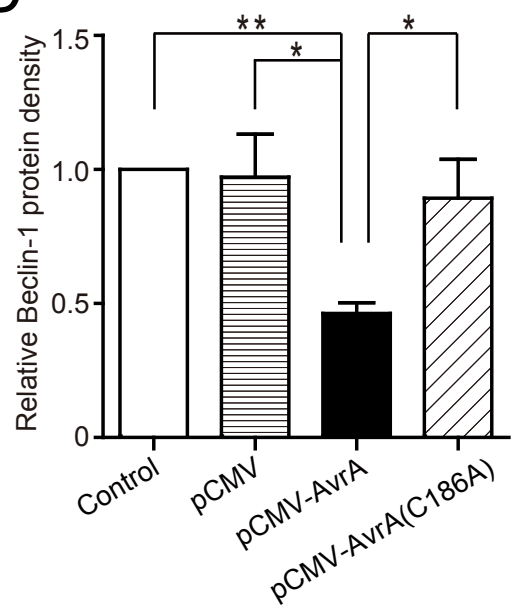


Fig. 3

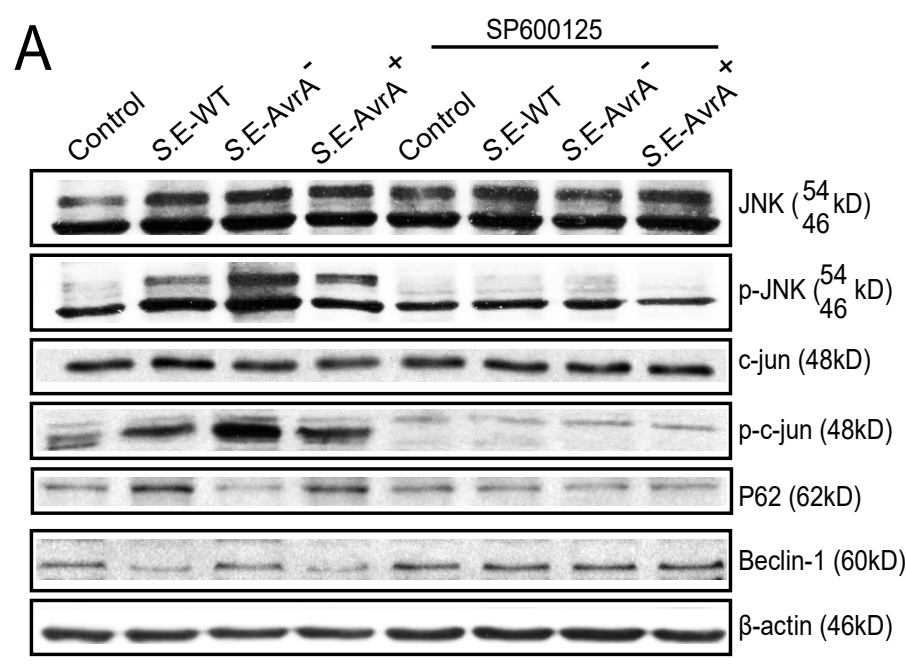

$\mathrm{B}$

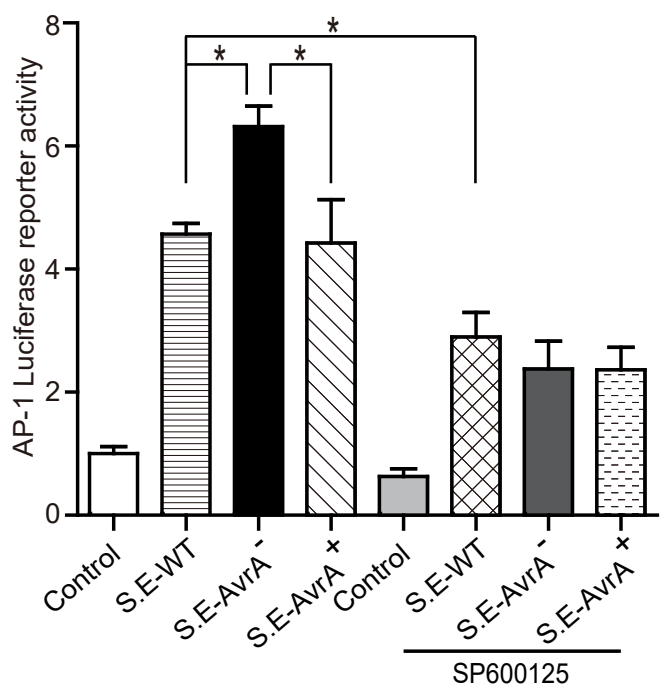


Fig. 4
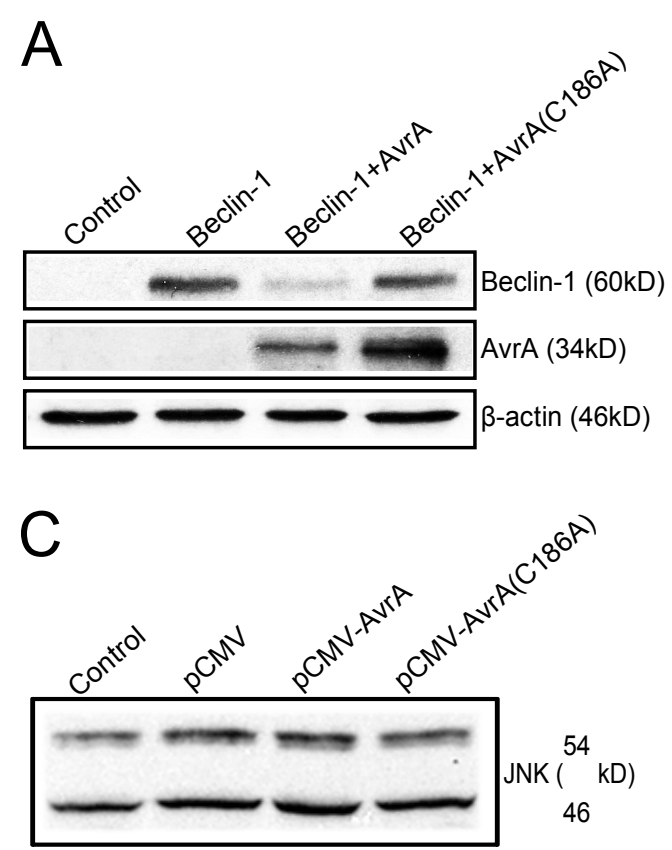

B
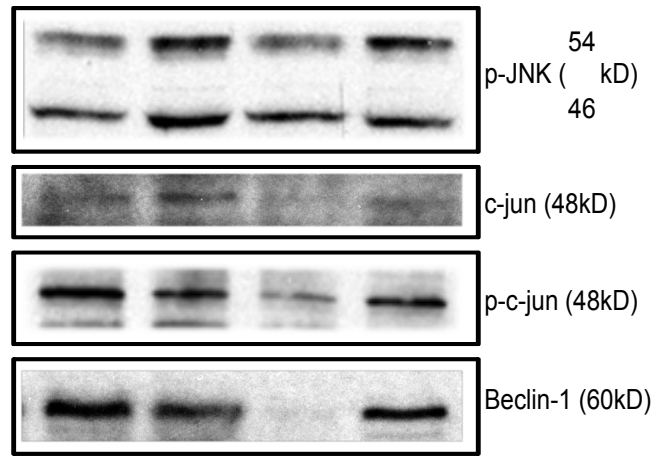

$\longrightarrow \infty-\infty$-actin $(46 \mathrm{kD})$ 
Fig. 5

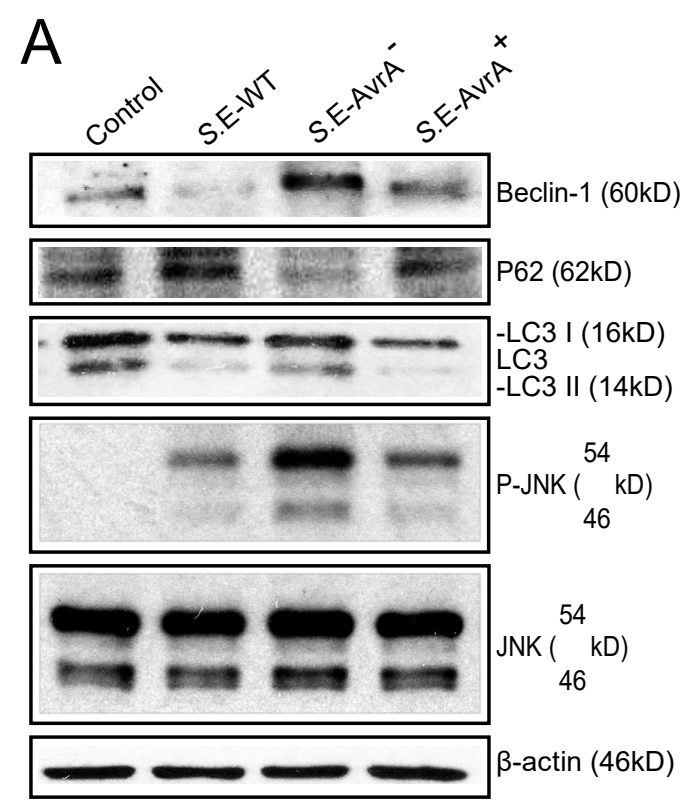

B

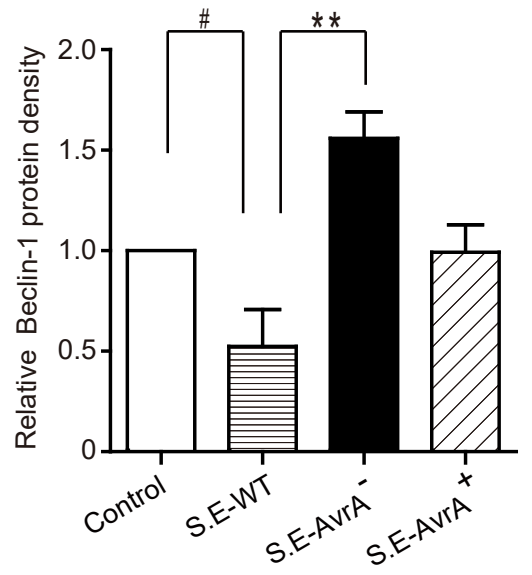

C

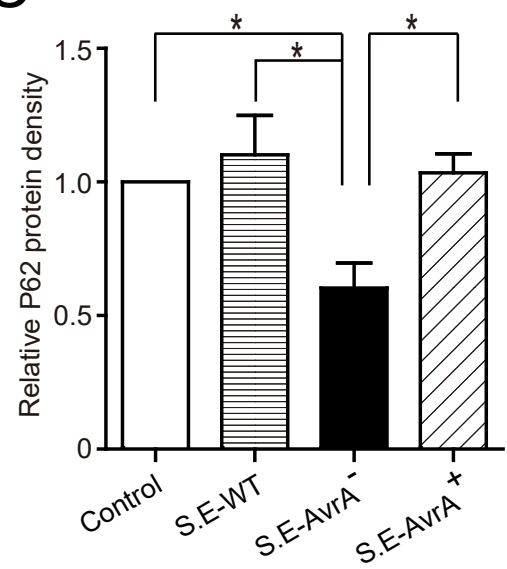

$D$

E
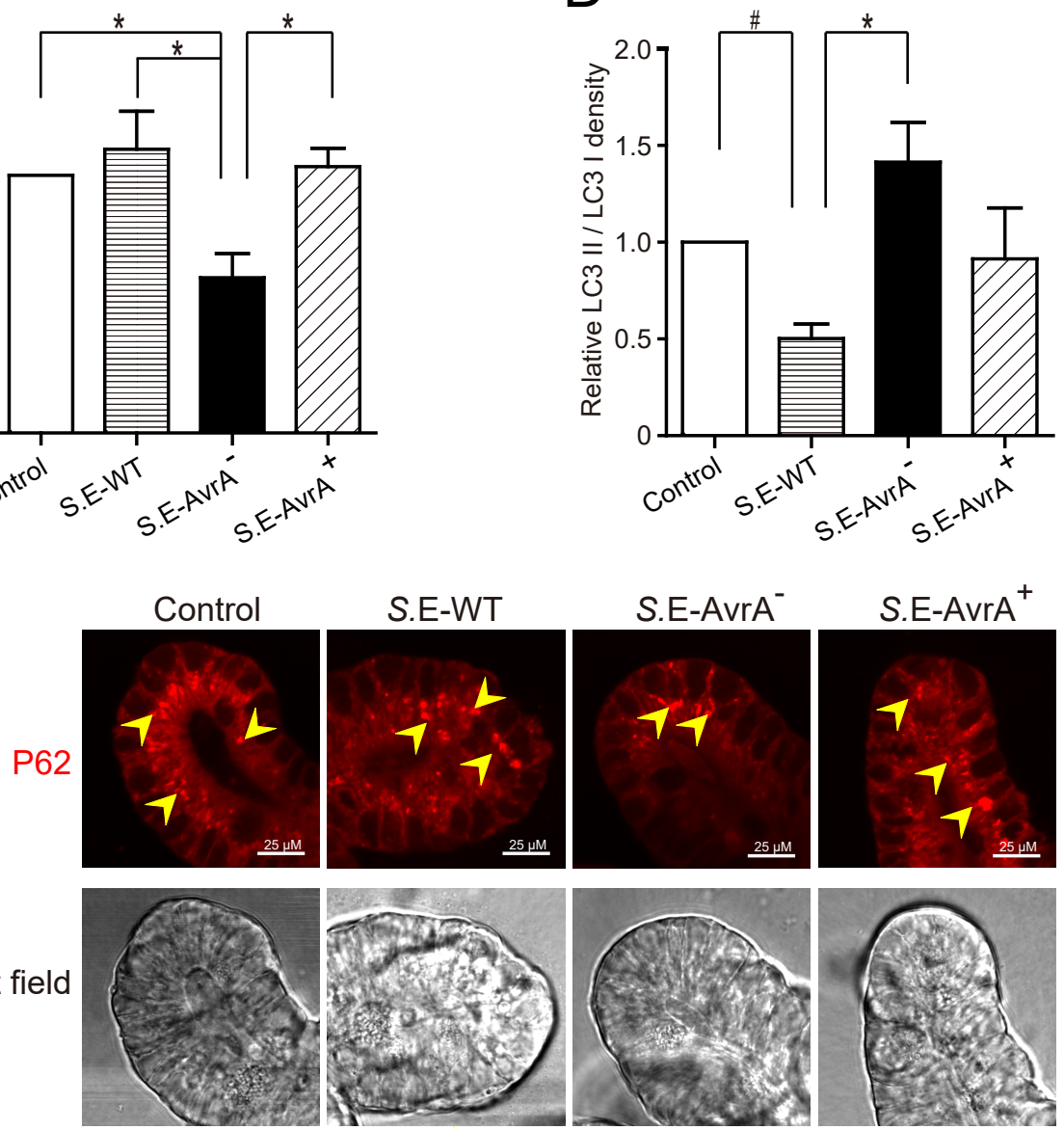

Bright field
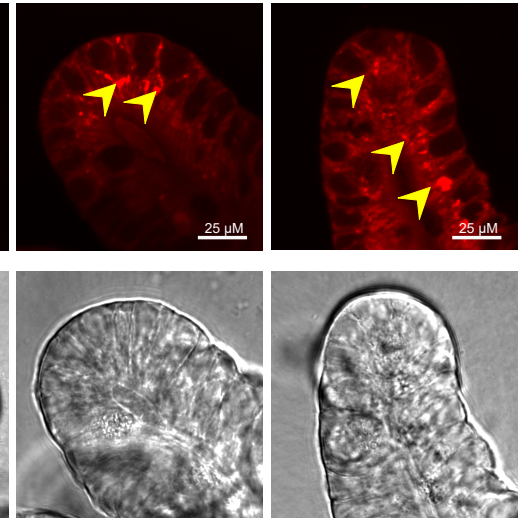
Fig. 6

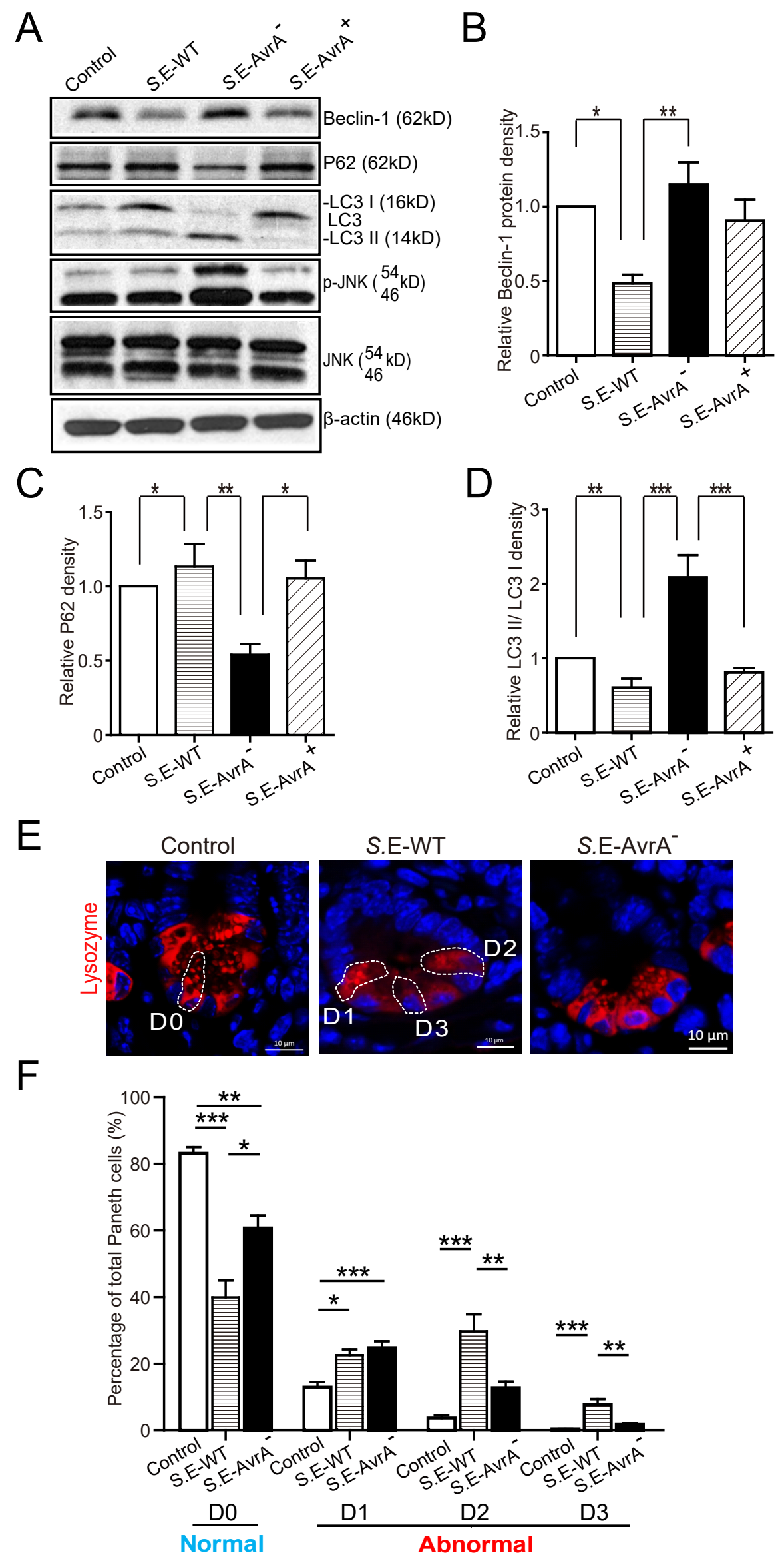


Fig. 7

\section{A}

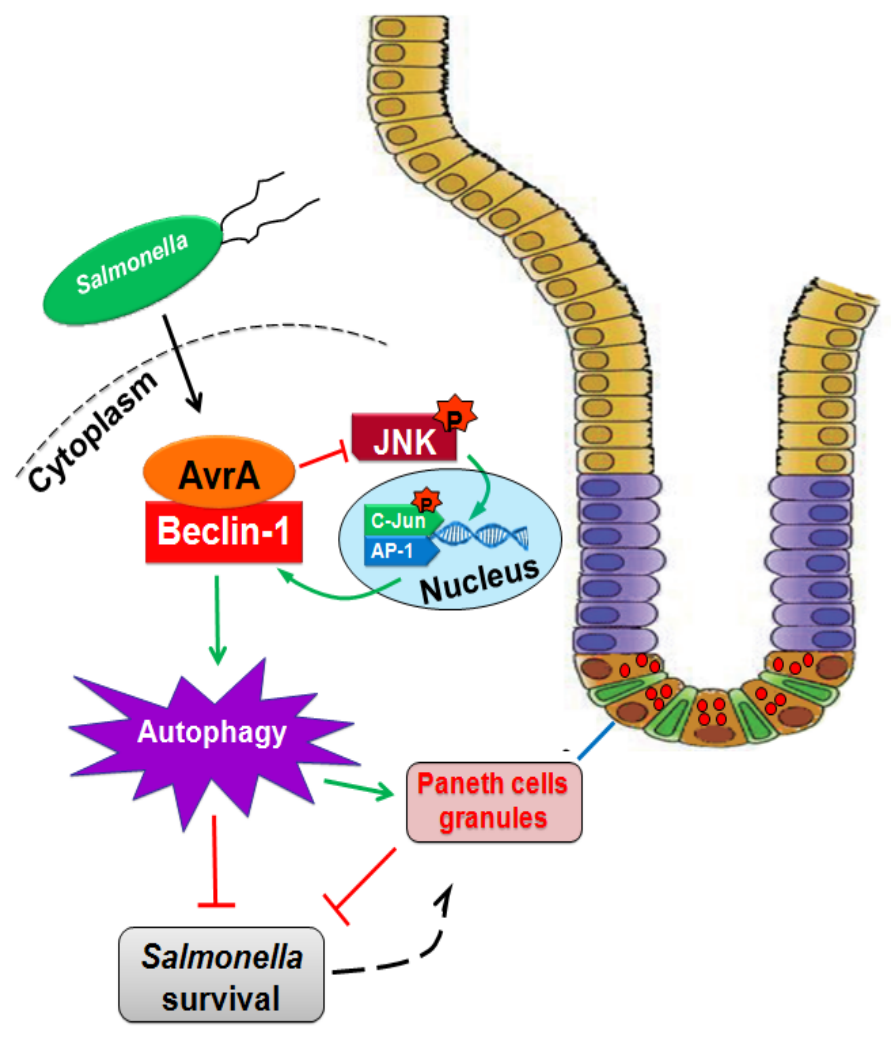

